\title{
BUSINESS
}

\section{Bridging the gap in the German economy}

$\square$ ermany's economic engine has seemed to be stalling of late - partly due, some say, to a breakdown in relations between science and industry.

One man in an excellent position to bring the two together is Günter Stock, head of research at Berlin-based pharmaceutical firm Schering. A physiologist with extensive contacts in academia and industry, Stock takes over next January as head of the BerlinBrandenburg Academy of Sciences.

Stock is already pondering how best to use his industrial experience to spruce up the academy. In the past few decades, he says, German society has lost its previous consensus that wealth and economic growth are closely linked to progress in science and technology. "Unfortunately, science in this country is often considered a troublemaker rather than a problem solver," he says.

Current angst over Germany's industrial strength contrasts sharply with the optimism of 1982, when Stock joined Schering's cardiovascular research unit. He traces the change, in part, to anti-science sentiment in the wake of the 1980s environmental movement and the Chernobyl accident. He plans to use his new role to forcefully remind the powers-that-be in politics, industry and finance that driving Germany's economy demands the re-engagement of science at all levels.

\section{Expertise where it counts}

In a country that lacks a national scientific academy, Stock thinks the Berlin academy can become a flagship institution for channelling expert scientific knowledge to focal areas of society. He aims to bring together expertise from different sources in ways that will be useful to society and government alike. In the past, he says, an array of diffuse opinions has too often confused the public, rather than helping to enlighten it.

Germany's initially cautious response to biotechnology is seen by Stock as an example of where the country has been going wrong. Even when the government launched the BioRegio competition in 1995, which opened door for many biotech entrepreneurs, it ended up with an "over-engineered" regulatory system whose "safety bureaucracy" has continued to stifle the sector's development, he says.

He hopes these mistakes won't be repeated

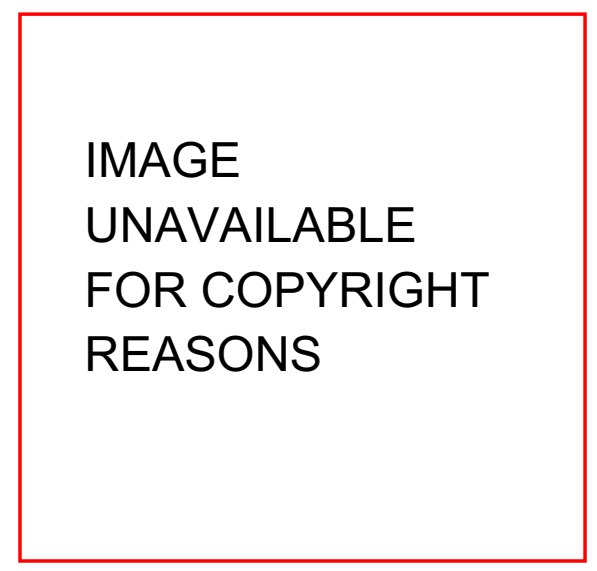

Joined-up thinking: Berlin academy head Günter Stock is urging science to re-engage with industry.

in emerging areas, such as nanotechnology. "What's needed is to carefully govern things in the process of doing them, rather than setting up rules and regulations in advance," he says.

Stock thinks that Germany's basic scientific landscape is in good shape, but that there's a divide between publicly funded researchers at the universities and Max Planck Institutes, and their colleagues in industrial laboratories. To bridge this, he hopes to make it easier for scientists to move between the two worlds. Federal and regional government could also help by setting up programmes to foster collaborations between industry and academia. $\mathrm{He}$ would like to see the government do more to support small research-based businesses, given the scarcity of private venture capital for such projects in Germany. "Seed capital doesn't like to flow in risky early phase research," he says.

Stock says that after next month's election, he will call on the new government to create a legal framework allowing academia and industry to grasp opportunities early on. He foresees big knock-on benefits: investment in science and technology will also help combat Germany's foremost social problem - unemployment.

His first task, he says, will be to update the academy's interests and long-term research projects. The most burning issues, he thinks, are the problems of an ageing population, molecular medicine and health, nanotechnology, and - in the social sciences - Islamism and conflict research. "We have a lot to offer," he says. Quirin Schiermeier

\section{IN BRIEF}

WEIGHT PROBLEMS The US Food and Drug Administration (FDA) has told a watchdog group that it will not ban Abbott Laboratories' Meridia, a weight-loss drug with $\$ 300$ million in global sales last year. Back in 2002, US consumer group Public Citizen petitioned the regulator to pull the drug from the market, arguing that its cardiovascular risks outweighed its benefits. But in a 9 August letter to the group, the FDA said that it couldn't attribute the heart attacks and strokes that have been reported in some patients to use of the drug, as such events are so common in obese patients anyway.

SELLING CHIPS Measurement company Agilent, based in Palo Alto, California, has said it will shed several businesses and concentrate on its core activity of making scientific instruments. The company, which was spun-off from Hewlett-Packard in 1999, lost billions of dollars when the hightech bubble burst and it has since shed some 12,000 staff. Now it is selling its microchip business and retreating from a joint venture with Royal Philips Electronics that makes light-emitting diodes. Bill Sullivan, its chief executive, predicted that the global market for scientific instruments - now worth about $\$ 40$ billion, of which Agilent has a large share - will grow by about $8 \%$ each year.

\section{BAD FOR BOSTON}

Massachusetts-based Boston Scientific, which makes medical devices, says it will stop making a drug-release device after receiving a second warning letter from the US Food and Drug Administration saying that the manufacturing procedure isn't good enough. The Vaxcel device is implanted in the chest, where it dispenses medicine in precise amounts. A previous letter to the same effect was sent in May. Also, studies published in The Journal of the American Medical Association and The New England Journal of Medicine have reported that the company's leading product, its drug-eluting Taxus stent, is not as effective in preventing the reclogging of coronary arteries as its arch-rival Cypher, made by Florida-based company Cordis, owned by Johnson \& Johnson. 